\title{
Gait Kinematics Index, Global Symmetry Index and Gait Deviations Profile: Concept of a new comprehensive method of gait pathology evaluation
}

\author{
KATARZYNA JOCHYMCZYK-WOŹNIAK ${ }^{1}$, KATARZYNA NOWAKOWSKA-LIPIEC ${ }^{1}$, \\ HANNA ZADON' ${ }^{1}$, SABINA WOLNY ${ }^{2}$, MAREK GZIK ${ }^{1}$, JOANNA GORWA ${ }^{3}$, ROBERT MICHNIK ${ }^{1}$ \\ ${ }^{1}$ Department of Biomechatronics, Faculty of Biomedical Engineering, Silesian University of Technology, Zabrze, Poland. \\ ${ }^{2}$ Students' Scientific Circle "Biokreatywni”, Faculty of Biomedical Engineering, \\ Silesian University of Technology, Zabrze, Poland. \\ ${ }^{3}$ Department of Biomechanics, Chair of Theory and Methodology of Sport, Faculty of Sport Sciences, \\ Poznan University of Physical Education, Poznań, Poland.
}

\begin{abstract}
Purpose: The objective of the work was to define a new comprehensive method of evaluating gait pathology (Gait Kinematics Index, Global Symmetry Index and Gait Deviations Profile). Methods: The article presents in detail a mathematical algorithm of a new comprehensive method of evaluating gait pathology. Input data for the algorithm are the kinematic parameters of gait. The method is based on the determination of the following parameters: standardized angular variables $\left(W_{j i}\right)$, kinematic indicators of gait $\left(\mathrm{KI}_{j}\right)$, gait cycle indicators $\left(\mathrm{GCI}_{i}\right)$, Gait Kinematic Index (GKI), Gait Deviations Profile (GDP, GDP ${ }_{j}$ ), Global Symmetry Index (GSI) and Symmetry Indices $\left(\mathrm{SI}_{j}\right)$ for kinematic gait values. The algorithm is based on the determination of the difference between results obtained in relation to the kinematics of movement of a given patient and the average value obtained in relation to the standard in each percentage of a gait cycle. The proposed method was tested using results obtained for 59 healthy persons and one patient with locomotor function disorder. Results: The GKI values for the reference group amounted to $0.89 \pm 0.23$. Information which can be obtained using the proposed gait assessment method was presented using an example of a patient with the disorder of locomotor functions. Areas of gait deviations, which were identified on the basis of the determined indicators, were presented in a graphic form using GDP. Conclusions: The new gait assessment method makes it possible to identify gait using a single numerical value, evaluate movements in individual joints and in subsequent moments as well as to assess the symmetry of gait.
\end{abstract}

Key words: gait analysis, gait index, kinematics, symmetry index

\section{Introduction}

The clinical assessment of gait is used for the functional evaluation of the patient's condition (diagnostics) as well as to determine the progress of postoperative, rehabilitation or pharmacological treatment. Also, it is used to analyse a uniform study group (in terms of a particular chronic condition) in order to describe the stereotype of gait characteristic of a given condition [1], [8], [9], [15], [19], [22].

Gait assessment is based on the results of observations or the results obtained using quantitative methods (movement analysis systems). The analysis of gait is based on time-spatial parameters, movements in individual joints at subsequent moments and on the symmetry of movement [3], [9], [10], [21], [22], [24], [26].

* Corresponding author: Katarzyna Nowakowska-Lipiec, Department of Biomechatronics, Faculty of Biomedical Engineering, Silesian University of Technology, ul. Roosevelta 40, 41-800 Zabrze, Poland. Phone: +48 3227774 36, e-mail: Katarzyna.Nowakowska -Lipiec@polsl.pl

Received: March 28th, 2020

Accepted for publication: September 10th, 2020 
The most common clinical method used to assess gait pathology is based on observation. For on experienced clinician, even the slightest deviations from proper gait are relatively easily visible. However, the above-named method is extremely subjective and encumbered with a significant error resulting, among other things, from the lack of experience of a person in charge of a test or the subconscious looking for previously assumed results. The lack of any standards, in terms of the assessment of irregularities, the manner of their description and elements to be taken into consideration results in the limited comparability of observation results during treatment. Although there are many observation-related scales of functional assessment (GMFCS, GMFM, PEDI, MACS, FAQ), these scales are subjective with the results depending directly on a person responsible for performing a given test [1], [5], [8]. Another difficulty connected with the use of such a form of gait assessment is the simultaneous observation of all body segments. Moreover, the significant variability of gait kinematics even at low gait velocity and the necessity of the simultaneous observation of joints of the lower limb and pelvis makes the proper performance of the aforesaid observation almost impossible [18].

The quantitative analysis based on the tests of gait kinematics involving the use of movement analysis systems provides information about gait in the form of numerical parameters enabling the assessment of the locomotor standard. Measurements of gait kinematics enable the determination of time-spatial parameters, course of pelvic positions and angles in joints presented against normative courses and dynamic parameters of gait. The results of the quantitative analysis of gait are usually made in the form of a report containing values along with a related description indicating deviations from the standard at characteristic moments of the gait cycle. The aforesaid results and description make it possible to formulate conclusions concerning the functioning of the muscular system. The quantitative analysis of gait provides many variables, the simultaneous analysis of which is difficult and time consuming. In addition, on the basis of the aforesaid variables it is difficult to unequivocally state whether the improvement or deterioration of the gait stereotype took place [9]. A solution to this problem can be found in gait indices assessing gait by means of one numerical value and, as a result, proving reliable in the assessment of treatment results [9], [10], [12]-[15]. The most popular indices of gait assessment include Gillette Gait Index (GGI) [17], Gait Deviation Index (GDI) [20], GDI-Kinetic [21], Gait
Profile Score (GPS) \& Movement Profile Score (MAP) [2], Gait Variability Index (GVI) [5,7], Symmetry Index (SI) [3], [16], [21] or Symmetry Function (SF) [24]. However, the above-named indices are not commonly used by clinicians, they are primarily applied in research-related tests. The most commonly used gait indices are characterised by complicated mathematical algorithms, the implementations of which appears difficult and laborious. Nearly all indices enable the assessment of gait by means of one non-dimensional numerical value without evaluating movements in individual joints and at successive moments. In addition, the most commonly used gait indices do not assess gait symmetry. By means of one numerical value, the aforesaid gait indices indicate patient's deviations from proper gait or make it possible to compare results from subsequent tests involving the same patient. However, they do not enable the determination of reasons for such deviations in relation to the areas of their presence.

Because of the foregoing, this study aims to present a concept a new comprehensive method of gait pathology evaluation (Gait Kinematics Index, Global Symmetry Index and Gait Deviations Profile). In addition to being expressed with one numerical value, this new method enables the assessment of movement in individual joints at successive moments and makes it possible to evaluate gait symmetry.

\section{Materials and methods}

\subsection{Algorithm of Gait Kinematics Index (GKI)}

To identify kinematic parameters making up the GKI, it is necessary to perform experimental measurements of gait using, e.g., optical, inert etc., movement analysis systems. Because of the fact that the GKI evaluates patient's deviation from proper gait, it is necessary to possess information about kinematic parameters for a representative group of persons without locomotor system dysfunctions.

The GKI is created on the basis of time courses of 11 kinematic parameters of gait $j$, i.e., ankle dors-plantarflexion (AFE), foot progression (AIE), knee flexionextension (KFE), knee valgus-varus (KAA), knee rotation (KIE), hip flexion-extension (HPFE), hip abduction-adduction (HPAA), hip rotation (HPIE), pelvic tilt (PTILT), pelvic obliquity (POBLI), pelvic rotation (PROT). 
In relation to each kinematic parameter $j$ it is necessary to calculate the absolute value of the difference between the value obtained in relation to a given patient and the average value obtained in relation to the standard in each percentage of gait cycle $i$. The standardized angular variable $\left(W_{j i}\right)$ is a quotient of the obtained difference and the value of standard deviation of a given kinematic value obtained in relation to the standard:

$$
W_{j i}=\frac{\left|M_{j i}-M_{n j i}\right|}{S D_{n j}}
$$

where: $j$ - kinematic parameter of gait subjected to analysis, $i$ - percentage of gait cycle, $n$ - standard, $M_{j i}$ - value of a given kinematic parameter of gait in the successive percentage of gait cycle in relation to the patient, $M_{n j i}$ - average of a given kinematic parameter of gait in the successive percentage of gait cycle in relation to the standard, $S D_{n j i}$ - standard deviation of a kinematic parameter of gait in the successive percentage of gait cycle in relation to the standard.

In relation to each kinematic parameter $j$, it is necessary to determine the gait kinematic index $\mathrm{KI}_{j}$, obtained in subsequent percentages of gait cycle $W_{j i}$ obtained in subsequent percentages of gait cycle $i$ in relation to given parameter $j$ :

$$
\mathrm{KI}_{j}=\frac{\sum_{i=0}^{i=100} W_{j i}}{101} .
$$

In addition, in each percentage of gait cycle, separately in relation to the right lower and left lower limb, it is also necessary to determine gait cycle index $\mathrm{GCI}_{i}$. Index $\mathrm{GCI}_{i}$ is the arithmetic mean of standardized angular variable $W_{j i}$ obtained in relation to all kinematic parameters $j$ in a given percentage of gait cycle $i$. As a result, 101 indices $\mathrm{GCI}_{i}$ in relation to the right lower limb and 101 indices $\mathrm{GCI}_{i}$ in relation to the left lower limb are obtained:

$$
\mathrm{GCI}_{i}=\frac{\sum_{j=1}^{j=11} W_{j i}}{11} .
$$

Gait Kinematic Index (GKI) is an arithmetic mean of indexes $\mathrm{GCI}_{i}$ obtained in successive percentages of gait cycle $i$ and determined separately for the right lower and left lower limb:

$$
\mathrm{GKI}=\frac{\sum_{i=0}^{i=100} \mathrm{GCI}_{i}}{101} .
$$

\subsection{Algorithm of Gait Deviations Profile (GDP) and classification of the results}

The global Gait Deviations Profile is developed on the basis of gait cycle indexes $\mathrm{GCI}_{i}$ obtained in each percentage of the gait cycle. To facilitate the analysis of results, the authors have developed a colour scale enabling the visual classification of the values of indexes.

The scale is divided into four levels where the green colour represents a normal result, the yellow colour indicates a borderline normal result, the orange colour stands for a result differing from normal and the red colour signifies a result widely differing from normal.

\begin{tabular}{|c|c|c|c|}
\hline & Colour & Value & Evaluation of the results \\
\hline 1 & $\begin{array}{c}\text { Green } \\
W_{j i} \leq 1 \\
\text { GKI } \leq \text { mean } \pm \text { std }\end{array}$ & $\begin{array}{c}W_{j i} \leq 1 \\
\mathrm{GKI} \leq 1.13\end{array}$ & Results in the norm \\
\hline 2 & $\begin{array}{c}\text { Yellow } \\
\text { mean } \pm \text { std }<\text { GKI } \leq \text { mean } \pm 2 * \text { std }\end{array}$ & $\begin{array}{c}1<W_{j i} \leq 2 \\
1.13<\mathrm{GKI} \leq 1.36\end{array}$ & Results at the limit of the norm \\
\hline 3 & $\begin{array}{c}\text { Orange } \\
\text { mean } \pm 2=\text { std }<\text { GKI } \leq \text { mean } \pm 3 * \text { std }\end{array}$ & $\begin{array}{c}2<W_{j i} \leq 3 \\
1.36<\mathrm{GKI} \leq 1.59\end{array}$ & Results beyond the norm \\
\hline 4 & $\begin{array}{c}\text { Red } \\
W_{i j}<3 \\
\text { mean } \pm 3 * \text { std }<\text { GKI }\end{array}$ & $\begin{array}{c}3<W_{j i} \\
1.59<\mathrm{GKI}\end{array}$ & Results beyond the norm significantly \\
\hline
\end{tabular}

The following values $\left(\mathrm{KI}_{j}, \mathrm{GCI}_{i}\right.$ and GKI) are classified into defined colour ranges on the basis of a distance

Table 1. Classification of results $W_{j i}$, GKI

$W_{j i}$ - standardized angular variable; GKI - Gait Kinematic Index; std - standard deviation. 
Table 2. Classification of results $\mathrm{KI}_{j}$

\begin{tabular}{|c|c|c|c|c|}
\hline$j$ & $\begin{array}{c}\text { Green } \\
\text { Results in the norm } \\
\mathrm{KI}_{j} \leq \text { mean } \pm \text { std }\end{array}$ & $\begin{array}{c}\text { Yellow } \\
\text { Results at the limit of the norm } \\
\text { mean } \pm \text { std }<\mathrm{KI}_{j} \leq \text { mean } \pm 2 * \text { std }\end{array}$ & $\begin{array}{c}\text { Orange } \\
\text { Results beyond the norm }\end{array}$ & $\begin{array}{c}\text { Red } \\
\text { Results beyond the } \\
\text { norm significantly } \\
\text { mean } \pm 2 * \text { std }<\mathrm{KI}_{j} \leq \text { mean } \pm 3 * \text { std }\end{array}$ \\
$\mathrm{KI}_{j}<$ mean $\pm 3 *$ std \\
\hline $\mathrm{AFE}$ & $\mathrm{KI}_{j} \leq 0.98$ & $0.98<\mathrm{KI}_{j} \leq 1.22$ & $1.22<\mathrm{KI}_{j} \leq 1.47$ & $1.47<\mathrm{KI}_{j}$ \\
\hline $\mathrm{AIE}$ & $\mathrm{KI}_{j} \leq 1.06$ & $1.06<\mathrm{KI}_{j} \leq 1.43$ & $1.43<\mathrm{KI}_{j} \leq 1.8$ & $1.8<\mathrm{KI}_{j}$ \\
\hline $\mathrm{KFE}$ & $\mathrm{KI}_{j} \leq 2.14$ & $2.14<\mathrm{KI}_{j} \leq 2.74$ & $2.74<\mathrm{KI}_{j} \leq 3.34$ & $3.34<\mathrm{KI}_{j}$ \\
\hline $\mathrm{KAA}$ & $\mathrm{KI}_{j} \leq 1,02$ & $1.02<\mathrm{KI}_{j} \leq 1.39$ & $1.39<\mathrm{KI}_{j} \leq 1.76$ & $1.76<\mathrm{KI}_{j}$ \\
\hline $\mathrm{KIE}$ & $\mathrm{KI}_{j} \leq 1.26$ & $1.26<\mathrm{KI}_{j} \leq 1.72$ & $1.72<\mathrm{KI}_{j} \leq 2.18$ & $2.18<\mathrm{KI}_{j}$ \\
\hline $\mathrm{HPFE}$ & $\mathrm{KI}_{j} \leq 1.75$ & $1.75<\mathrm{KI}_{j} \leq 2.26$ & $2.26<\mathrm{KI}_{j} \leq 2.77$ & $2.77<\mathrm{KI}_{j}$ \\
\hline $\mathrm{HPAA}$ & $\mathrm{KI}_{j} \leq 1.17$ & $1.17<\mathrm{KI}_{j} \leq 1.58$ & $1.58<\mathrm{KI}_{j} \leq 1.98$ & $2.98<\mathrm{KI}_{j}$ \\
\hline PTILT & $\mathrm{KI}_{j} \leq 1.21$ & $1.21<\mathrm{KI}_{j} \leq 1.63$ & $1.63<\mathrm{KI}_{j} \leq 2.04$ & $2.5<\mathrm{KI}_{j}$ \\
\hline POBLI & $\mathrm{KI}_{j} \leq 1.41$ & $1.41<\mathrm{KI}_{j} \leq 1.96$ & $1.96<\mathrm{KI}_{j} \leq 2.5$ & $1.93<\mathrm{KI}_{j}$ \\
\hline PROT & $\mathrm{KI}_{j} \leq 1.19$ & $1.19<\mathrm{KI}_{j} \leq 1.56$ & $1.76<\mathrm{KI}_{j} \leq 1.93$ & $2.11<\mathrm{KI}_{j}$ \\
\hline
\end{tabular}

$\mathrm{KI}_{j}$ - gait kinematic index, $j$ - kinematic parameter of gait subjected to analysis, std - standard deviation, PTILT - pelvic tilt, POBLI - pelvic obliquity, PROT - pelvic rotation, HPFE - hip flexion-extension, HPAA - hip abduction-adduction, HPIE - hip rotation, KFE - knee flexion-extension, KAA - knee valgus-varus, KIE - knee rotation, AFE - ankle dors-plantarflexion, AIE - foot progression.

of the result from the mean value obtained for the reference group in accordance with the values of subsequent standard deviations (std) identified for the reference group (Tables 1-2). Boundary values for individual ranges are presented in Tables 1-2. In the same way we determined the boundary values for $\mathrm{GCI}_{i}$, in subsequent 101 per cent of the gait cycle.

On the other hand, values 1, 2, 3 classify the obtained results $W_{j i}$ to subsequent colour ranges due to their normalization in relation to the value of standard deviation obtained for the reference group (Table 1).

GDP is presented in the form of two bars, showing values of $\mathrm{GCI}_{i}$ using the above-named scale of colours, separately for the right lower and the left lower limb.

Gait Deviations Profile is also identified in relation to each kinematic parameter $j$ making up GKI. GDP ${ }_{j}$ presents the values of standardized angular variable $W_{j i}$ within the adopted scale of colours, separately for the right lower and the left lower limb.

The results presented in the aforesaid manner make it possible to easily identify patient's gait deviation from the standard in each percentage of the cycle.

\subsection{Algorytm of Global Symmetry Index (GSI) and Symmetry Indices $\mathbf{S I}_{j}$ for kinematic gait values}

The global symmetry index is determined as a percentage difference between the value of GKI obtained for the right lower and left lower limb in accordance with the formula (5):

$$
\mathrm{GSI}=\frac{\left|\mathrm{GKI}^{L}-\mathrm{GKI}^{R}\right|}{0.5 *\left(\mathrm{GKI}^{L}+\mathrm{GKI}^{R}\right)} * 100 \%,
$$

where: $\mathrm{GKI}^{L}$ - value of GKI obtained in relation to the left lower limb, GKI ${ }^{R}$ - value of GKI obtained in relation to the right lower limb.

The symmetry index is also determined in relation to each kinematic parameter $j$ making up GKI based on the value of kinematic index of gait $\mathrm{KI}_{j}$, in accordance with the formula (6):

$$
\mathrm{SI}_{j}=\frac{\left|\mathrm{KI}_{j}^{L}-\mathrm{KI}_{j}^{R}\right|}{0.5 *\left(\mathrm{KI}_{j}^{L}+\mathrm{KI}_{j}^{R}\right)} * 100 \%,
$$

where: $\mathrm{KI}_{j}^{L}$ - value of the kinematic index in relation to a given kinematic parameter $j$ in relation to the left lower limb, $\mathrm{KI}_{j}^{R}$ - value of the kinematic index in relation to a given kinematic parameter $j$ in relation to the right lower limb.

The value of symmetry index amounting to zero represents complete symmetry, whereas a value deviating from zero indicates asymmetry [3].

\subsection{A new comprehensive method of gait pathology evaluation - a software programme in the Matlab environment}

The mathematical algorithm enabling the calculation of $W_{j i}, \mathrm{KI}_{j}, \mathrm{GCI}_{i}$, and GKI as well as symmetry indexes GSI and $\mathrm{SI}_{j}$ is implemented in the MatLab 
environment (MathWorks Inc., Massachusetts, USA). The programme also makes it possible to present the global Gait Deviations Profile and $\mathrm{GDP}_{j}$ in relation to each kinematic parameter in the form of coloured bars (for the right lower and left lower limb) in accordance with the adopted manner of result classification by means of the coloured scale (Table 1).

The first step to using the programme involves feeding the database of averaged results of kinematic parameters $j$ and their standard deviations in successive cycles of gait in relation to the representative group of healthy individuals (without locomotor system dysfunctions). Next, it is necessary to enter the symbol of a person, the gait of whom is to be assessed using the new comprehensive method of gait pathology evaluation.

In the software programme it is possible to import files related to a given person along with recorded kinematic parameters $j$ collected from several cycles of gait (several walks) in the *emt format. The values of kinematic parameters in the cycle of gait recorded in relation to several walks are averaged and constitute input data used to determine GKI.

The software programme downloads the value of indexes $W_{j i}, \mathrm{KI}_{j}, \mathrm{GCI}_{i}$ and GKI separately for the right lower and left lower limb and values of symmetry indexes GSI, and $\mathrm{SI}_{j}$. The results are saved in a selected *.xlsx file. The programme also enables the generation and storage of diagrams presenting the Gait Deviations Profile and $\mathrm{GDP}_{j}$ in relation to each kinematic parameter $j$.

\subsection{Study group}

The database of normative values related to indexes $W_{j i}, \mathrm{KI}_{j}, \mathrm{GCI}_{i}$, GKI, GSI, $\mathrm{SI}_{j}$ was developed on the basis of gait results obtained for a 59-strong study group of 30 males and 29 females aged $21.98 \pm 2.19$. The characteristics of the individuals are presented in Table 3. All of the persons expressed their consent to participate in the tests. All participants were healthy and free from any locomotor system dysfunctions or abnormalities of the body posture. To present a new way of results interpretation in this new complex method of gait pathology evaluation, the analysis also involved a patient with visible locomotor system dysfunctions. The patient was a 33 male (Table 2) whose spinal vertebrae (as a result of an injury) had been fractured in the cervical segment $(\mathrm{C} 3-\mathrm{C} 4)$, thoracic segment (Th2-Th5) and transverse processes within L4-L5. As a result of the trauma, the injured male suffers from numerous ailments including the hyper- aesthesia of the right half of the thorax, abdomen and feet and spastic paresis with contractures in the joints of the lower limbs.

Table 3. Study group characteristics

\begin{tabular}{|c|c|c|}
\hline \multicolumn{3}{|c|}{ Study group } \\
\hline Number ( $\mathrm{F}$ - female, $\mathrm{M}$ - male) & $\mathrm{F}=29$ & $\mathrm{M}=30$ \\
\hline Age [years] & \multicolumn{2}{|c|}{$21.98 \pm 2.19$} \\
\hline Body height $[\mathrm{m}]$ & \multicolumn{2}{|c|}{$1.75 \pm 0.09$} \\
\hline Body mass $[\mathrm{kg}]$ & \multicolumn{2}{|c|}{$69.26 \pm 13.63$} \\
\hline \multicolumn{3}{|c|}{ Case study } \\
\hline Sex $(F-$ female, $M-$ male $)$ & \multicolumn{2}{|c|}{$\mathrm{M}$} \\
\hline Age [years] & \multicolumn{2}{|c|}{33} \\
\hline Body height $[\mathrm{m}]$ & \multicolumn{2}{|c|}{1.78} \\
\hline Body mass $[\mathrm{kg}]$ & \multicolumn{2}{|c|}{60} \\
\hline
\end{tabular}

\subsection{Method of experimental measurements}

Gait was recorded using the BTS Smart optoelectronic system (BTS S.p.A., Milanese, IT, Italy) composed of six infrared cameras (sampling rate of $250 \mathrm{~Hz}$ ), a camera capturing video images, two dynamometric platforms (Kistler Eastern Europe s.r.o., Prague, Czech Republic, sampling rate of $1000 \mathrm{~Hz}$ ) and a control unit provided with a software programme coordinating the operation of the entire measurement equipment.

The interview and anthropometric measurements were followed by the attachment of nineteen passive markers on the body of each person qualified for the test. The arrangement of the markers on the body corresponded to anatomical points characterised by the Davis protocol [25]. In accordance with the Davis protocol, the markers were placed on the head of the fifth metatarsal bone, external lateral ankles, calcaneal tubers (for the static test), lateral epicondyli of the femoral bone, heads of calf bones, trochanter, anterior iliac spines, sacral bone and on the tibia and thigh (markers on extension arms).

After the performance of the static test, the individuals were requested to walk on a measurement path equipped with two dynamometric platforms (Kistler) recording ground response variables. The test was regarded as completed after the obtainment of a minimum of 10 acceptable trials (walks) for each person. Data collection was recorded in relation to gait at a preferable speed without footwear. Information collected during free gait was then processed in the BTS Smart Tracker and Analyzer software programmes (BTS S.p.A., Mil- 
anese, IT, Italy). As a result, it was possible to obtain values of dynamic and time-spatial parameters. The obtained kinematic parameters of gait constituted input data used to determine values of indexes $W_{j i}$, $\mathrm{KI}_{j}, \mathrm{GC}_{i}$, GKI, GSI, and $\mathrm{SI}_{j}$ global Gait Deviations Profile and $\mathrm{GDP}_{j}$ in relation to each kinematic parameter $j$.

This study was approved by the ethical committee of the Jerzy Kukuczka Academy of Physical Education in Katowice (protocol number 3/2019).

\section{Results}

\subsection{Reference group}

The computational procedure implemented in the MatLab environment programme enabled the identification of values of indices $W_{j i}, \mathrm{KI}_{j}, \mathrm{GCI}_{i}$, and GKI separately in relation to the right lower and left lower limbs and values of symmetry indices GSI, and $\mathrm{SI}_{j}$ in relation to the group of the individuals without locomotor system dysfunctions. As the tests involved persons not suffering from locomotor systems dysfunctions, the values of $W_{j i}, \mathrm{KI}_{j}, \mathrm{GCI}_{i}$, and GKI obtained in relation to the cycle of gait for the right lower and left lower limbs were averaged (Table 4, Fig. 1).
Table 4. Values of indices $\mathrm{KI}_{j}$, GKI, $\mathrm{SI}_{j}$ and GSI for the reference group

\begin{tabular}{|c|c|c|}
\hline$j$ & $\mathrm{KI}_{j}$ & $\mathrm{SI}_{j}$ \\
\hline PTILT & $0.87 \pm 0.55$ & $0.39 \%$ \\
\hline POBLI & $0.82 \pm 0.37$ & $0.28 \%$ \\
\hline PROT & $0.92 \pm 0.39$ & $0.25 \%$ \\
\hline HPFE & $1.24 \pm 0.51$ & $2.18 \%$ \\
\hline HPAA & $0.77 \pm 0.41$ & $1.83 \%$ \\
\hline HPIE & $0.79 \pm 0.42$ & $27.75 \%$ \\
\hline KFE & $1.55 \pm 0.59$ & $2.19 \%$ \\
\hline KAA & $0.65 \pm 0.37$ & $19.82 \%$ \\
\hline KIE & $0.79 \pm 0.46$ & $23.24 \%$ \\
\hline AFE & $0.73 \pm 0.24$ & $12.03 \%$ \\
\hline AIE & $0.68 \pm 0.37$ & $9.69 \%$ \\
\hline GKI & \multicolumn{2}{|c|}{$0.89 \pm 0.24$} \\
\cline { 2 - 3 } GSI & \multicolumn{2}{|c|}{} \\
\hline
\end{tabular}

$\mathrm{KI}_{\mathrm{j}}$ - gait kinematic index, GKI - Gait Kinematic Index, $\mathrm{SI}_{\mathrm{j}}$ - Symmetry Indices, GSI - Global Symmetry Index, PTILT - pelvic tilt, POBLI - pelvic obliquity, PROT - pelvic rotation, HPFE - hip flexion-extension, HPAA - hip abduction-adduction, HPIE - hip rotation, KFE - knee flexion-extension, KAA - knee valgus-varus, KIE - knee rotation, AFE - ankle dors-plantarflexion, AIE - foot progression, $j$ - kinematic parameter of gait subjected to analysis.

The mean value of GKI in relation to the reference group amounted to $0.89 \pm 0.23$. Based on the adopted criterion of gait classification it was revealed that the results of $75 \%$ of persons from the refer group did not

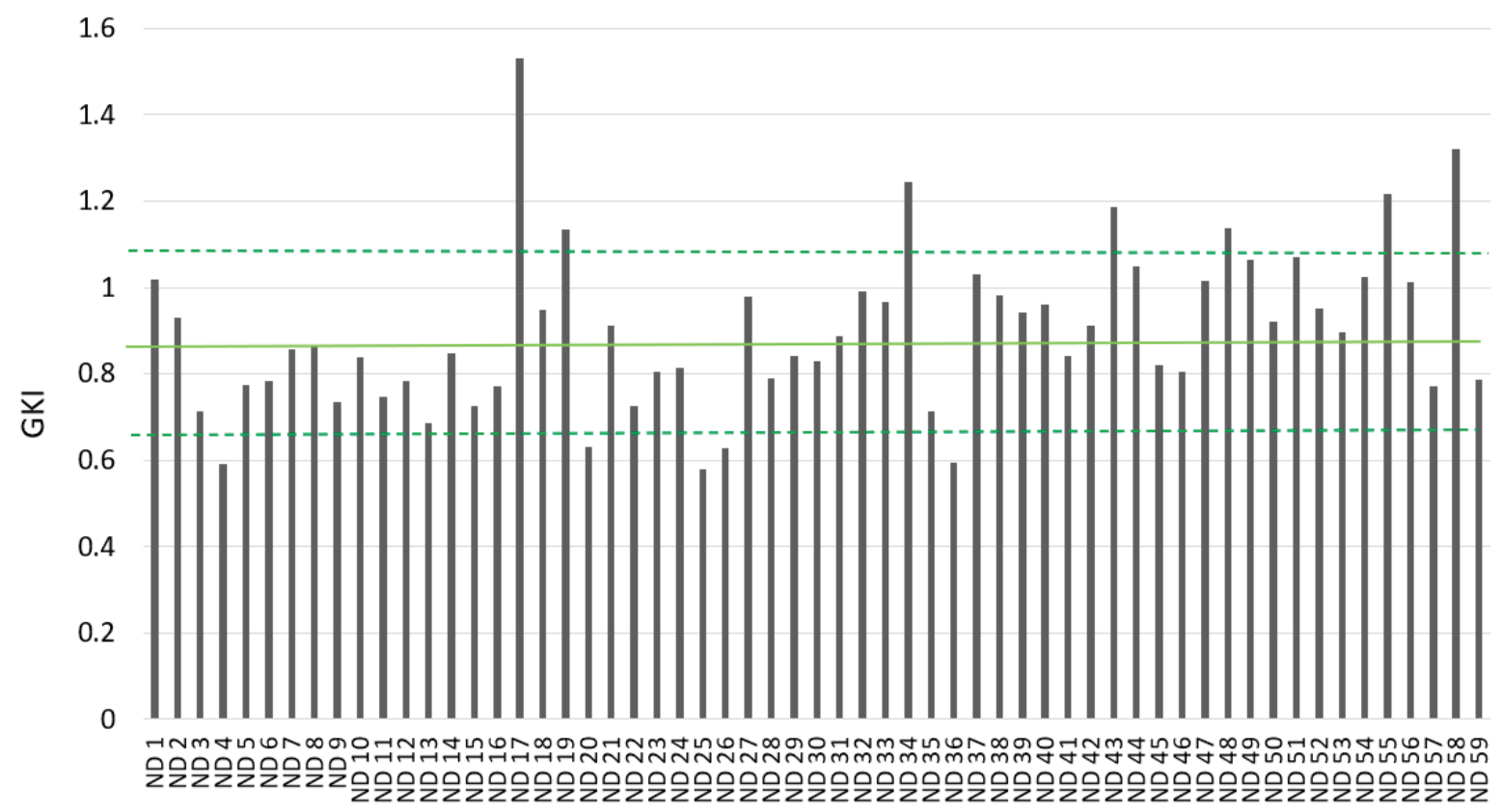

Fig. 1. Values of GKI in relation to each person from the reference group (ND) 
exceed GKI $\leq 1$, thus obtaining the best of expected results. The values related to the remaining persons did not exceed $2(\max G K I=1.55)$.

\subsection{Case study}

To present the manner of interpreting results obtained by means of the new comprehensive method of gait pathology evaluation, the analysis involved a patient with visible locomotor system dysfunctions. The courses of kinematic parameters and values of $\mathrm{KI}_{j}, \mathrm{GDP}_{j}$, GDP, GKI, SI $j$, GSI, which were classified in accordance with the adopted coloured scale, are presented in Table 5.
The value of GKI for the patient (gait cycle for the right lower limb amounting to 1.57 and that for the left lower limb being 1.62) is nearly twice higher than the mean value obtained in relation to the reference group. The GDP analysis revealed that the highest deviation from the standard was restricted within the range of $60 \%$ to $72 \%$ of the gait cycle (Initial Swing phase); the deviation was classified within the 2-3 range marked orange (Table 5). Detailed information is provided by the values of standardized angular variable $W_{j i}$ classified in accordance with the coloured scale (Table 1). They are usually identical to the previously presented angular courses and enable the explicit assessment of the kinematic parameters of gait. The greatest deviations from the

Table 5. Report containing results collected using the new method of gait pathology evaluation based on $\mathrm{KI}_{j}, \mathrm{GDP}_{j}, \mathrm{GDP}, \mathrm{GKI}, \mathrm{SI}_{j}$ and GSI for the test patient

\begin{tabular}{|c|c|c|c|c|}
\hline$j$ & Motion kinematics & $\mathrm{GDP}_{j}$ & $\mathrm{KI}_{j}$ & $\mathrm{SI}_{j}$ \\
\hline PTILT & 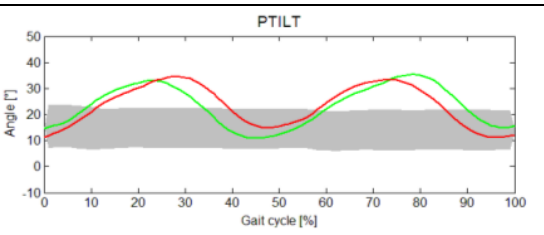 & 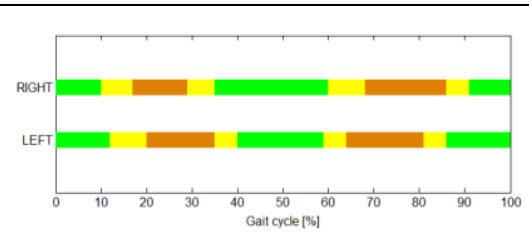 & $\begin{array}{l}R: 1.25 \\
L: 1.26\end{array}$ & $1 \%$ \\
\hline POBLI & 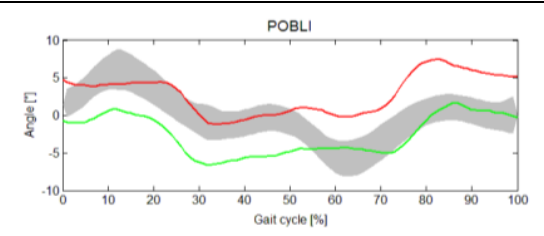 & 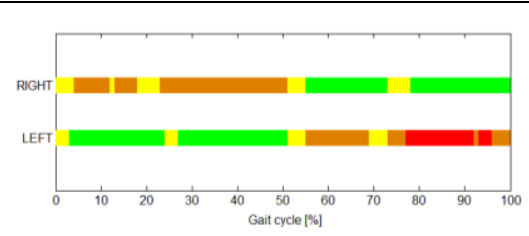 & $\begin{array}{l}R: 1.44 \\
L: 1.56 \\
\end{array}$ & $8 \%$ \\
\hline PROT & 200 & 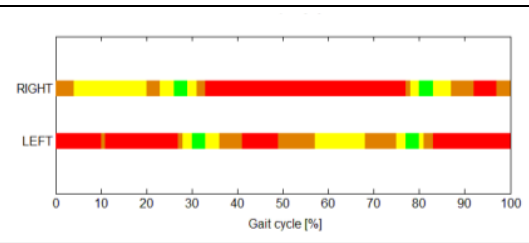 & & $3 \%$ \\
\hline HPFE & 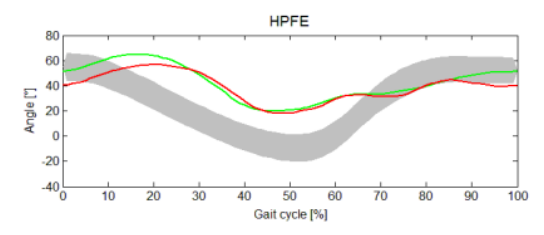 & 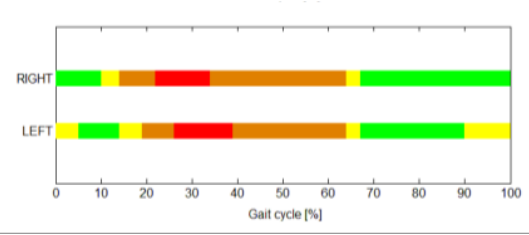 & $\begin{array}{l}\text { R: } 1.67 \\
L: 1.74 \\
\end{array}$ & $4 \%$ \\
\hline HPAA & 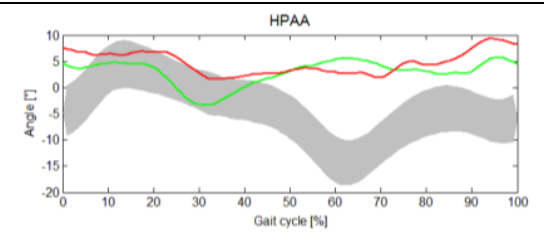 & 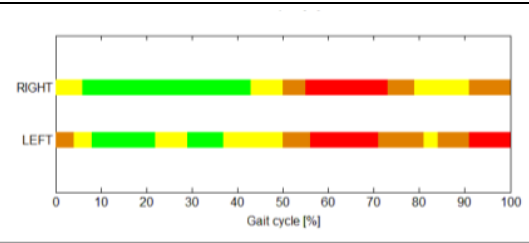 & $\begin{array}{l}\text { R: } 1.77 \\
L: 2.09\end{array}$ & $17 \%$ \\
\hline HPIE & 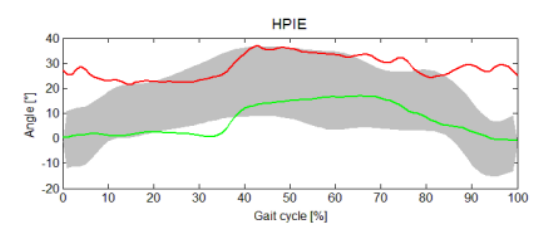 & 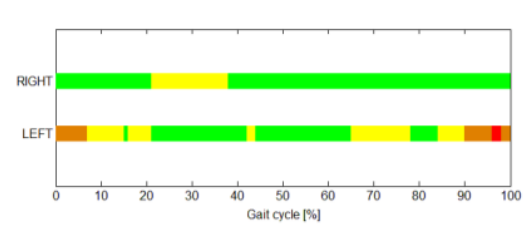 & \begin{tabular}{|l|} 
R: 0.54 \\
L: 1.27 \\
\end{tabular} & $80 \%$ \\
\hline
\end{tabular}


Table 5 continued

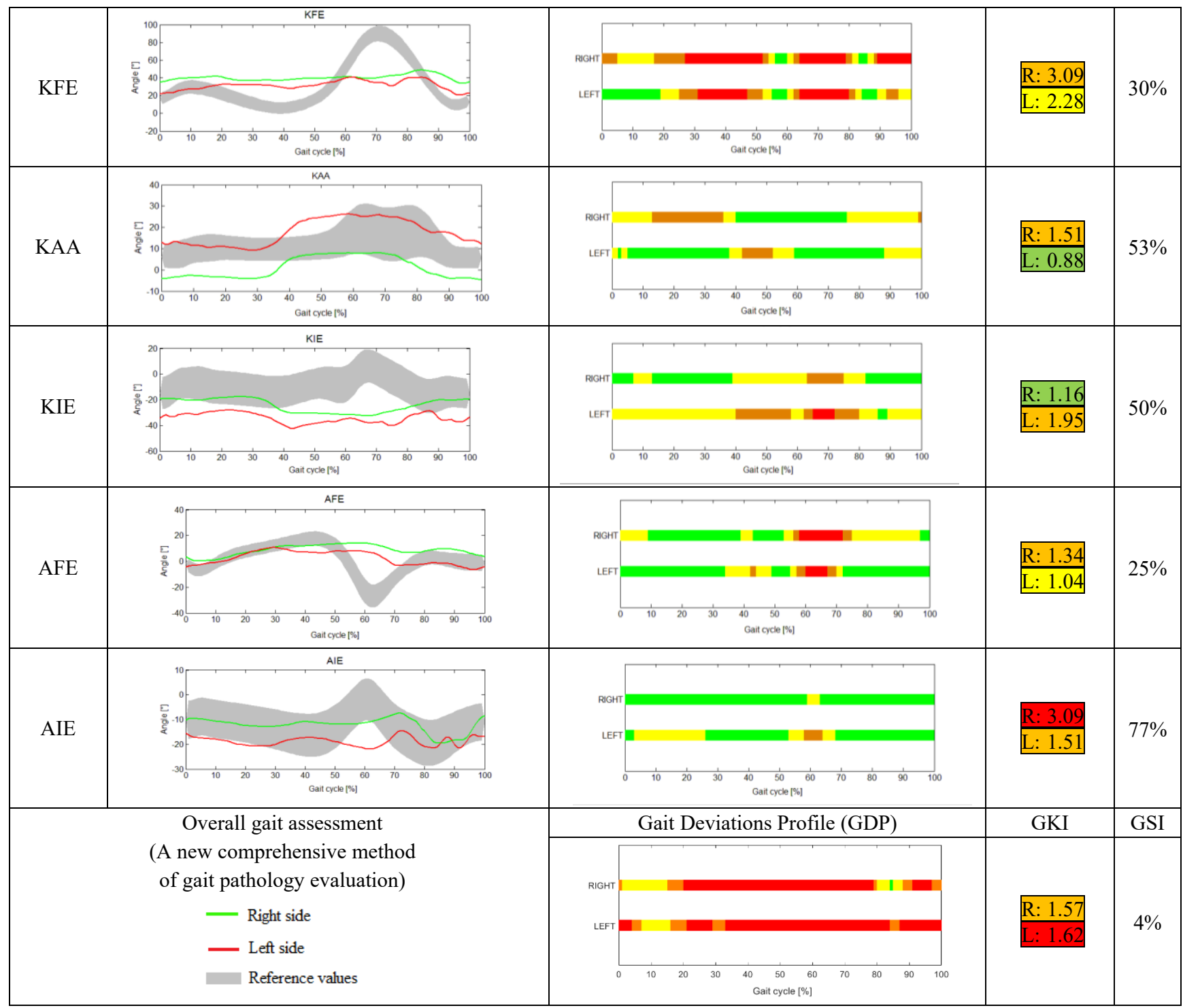

$j$ - kinematic parameter of gait subjected to analysis, GDP - Gait Deviaton Profile, $\mathrm{GDP}_{j}$ - GDP in relation to each kinematic parameter $j, \mathrm{KI}_{j}$ - gait kinematic index, $\mathrm{SI}_{j}$ - Symmetry Indices, GSI - Global Symmetry Index, GKI - Gait Kinematic Index, PTILT - pelvic tilt, POBLI - pelvic obliquity, PROT - pelvic rotation, HPFE - hip flexion-extension, HPAA - hip abduction-adduction, HPIE - hip rotation, KFE - knee flexion-extension, KAA - knee valgus-varus, KIE - knee rotation, AFE - ankle dors-plantarflexion, AIE - foot progression.

standard during the Initial Swing phase were recorded in relation to the flexion-extension movement in the ankle and in the knee joint, adduction-abduction in the hip joint, rotation in the right knee joint and pelvic rotation, for which the values of $W_{j i}$ exceeded 3. The analysis of $W_{j i}$ revealed that in relation to certain defined kinematic parameters, the indexes adopted values significantly varying from the standard (marked with the red colour) also in the remaining phases of gait. As a result, the gait deviations profile (Table 5) related to the remaining phase of the cycle was marked yellow (as borderline normal).

\section{Discussion}

The research work discussed in the article aimed to develop a new comprehensive method of gait pathology evaluation, including Gait Kinematics Index (GKI), Global Symmetry Index (GSI) and Gait Deviations Profile (GDP). This new method not only provides information of gait assessment in the form of a single numerical value but also presents results in a clear graphic form. The proposed form of analysis enables the indication of deviations from the standard in relation to a specific joint and percentage of the gait cycle 
as well as makes it possible to assess the symmetry of gait.

The proposed GKI is based on eleven kinematic parameters recorded during gait and informing about changes of angles in the ankle, knee joint, hip joint and pelvic movements in three planes. As the algorithm used for the identification of the value of GKI is relatively simple, it eliminates the risk of improper assessment as a result of a methodological error. The interpretation of results presented in a graphic form (GDP) is based on biomechanical knowledge (gait phases). These features make this method a simple and objective tool for physiotherapists and physicians. The graphic system of classification of the obtained index values is characterised by high clarity. The tests involved the determination of the values of GKI ( 0.89 \pm 0.23 ) for the reference group. Information which can be obtained through the analysis of values of $\mathrm{KI}_{j}$, GKI, $\mathrm{SI}_{j}, \mathrm{GSI}, \mathrm{GDP}$ and $\mathrm{GDP}_{j}$ for each kinematic parameter $j$ is presented in relation to the patient with locomotor system dysfunctions (Table 5).

Similarly to other indicative methods (GGI, GDI, GDI-Kinetic, GPS, GVI) [2], [5], [7], [19]-[21], the new comprehensive method of evaluating gait pathology makes it possible to globally characterise gait by means of a single numerical value of GKI. In the case subjected to analysis, the value of GKI in relation to the right lower limb amounts to 1.57 and 1.62 in relation to the left lower limb. In accordance with the coloured scale (Table 1), the above-presented values were classified as representing a borderline normal result (yellow colour). The values of GKI were identified on the basis of $\mathrm{GCI}_{i}$, assessing locomotor functions in each percentage of the gait cycle. The classification of the values of $\mathrm{GCI}_{i}$ in accordance with the adopted coloured scale constitutes the Gait Deviations Profile. The GDP can be used to indicate patient's gait deviations from the standard in relation to each percentage of the gait cycle. Such an assessment is not possible using any other index described in available scientific publications. On the basis of GDP it is possible to state that the patient's greatest deviations from the gait standard are contained between $60 \%$ and $75 \%$ of the gait cycle, i.e., at the moment the gait stance phase turns into the swing phase. In relation to the left limb, greater deviations from the standard gait were also observed in the terminal swing.

The method also enables a more precise assessment of gait, based on values $\mathrm{KI}_{j}$. Indices $\mathrm{KI}_{j}$ are determined for each kinematic parameter (P1-P11) as the mean value of standardized angular variables $W_{j i}$ related to a given parameter. Indices $\mathrm{KI}_{j}$ are also classified in accordance with the coloured scale. In terms of the case subjected to analysis, the highest values of $\mathrm{KI}_{j}$ (marked orange and red), indicating dysfunctions, were recorded for the kinematic parameters PROT and HPAA in relation to the left lower limb and KFE and AIE in relation to the right lower limb.

The only indicative methods enabling the assessment of gait based on partial parameters characterising movement in a given joint are the index of GPS [2] and Movement Deviation Profile (MDP) [3].The partial values of GPS presented in the form of MAP (Movement Analysis Profile) are used for the comparison of 9 kinematic parameters of the patient's gait (the same as those taken into consideration in the identification of GDI) with the average values of the aforesaid parameters related to the group of persons with proper gait. The above-named maps are presented in the form of a bar chart, on the basis of which it is only possible to indicate deviations from the standard in relation to a specific joint. The graphic interpretation of the individual parameters makes it possible to notice which variables contribute to an increase in the GPS index [2]. The advantages of the gait assessment method proposed by the authors and involving the use of the Gait Deviations Profile presented in the coloured scale consists in showing patient's deviations from the standard gait in each percentage of the gait cycle. Coloured profiles of deviations from the standard gait are presented in relation to each kinematic parameter (P1-P11) subjected to analysis. The analysis of $\mathrm{GDP}_{j}$ enables both detailed and intuitive assessment of the patient's gait kinematics in each percentage of the gait cycle.

The final element of the proposed method is the Global Symmetry Index (GSI), determined on the basis of values of GKI in relation to the right lower and left lower limb. In relation to the patient subjected to the tests, the value of GSI amounted to $4 \%$, indicating, that, generally, the patient's gait can be recognised as symmetric. For each kinematic parameter subjected to analysis, the index of symmetry SI is calculated based on the values $\mathrm{KI}_{j}$ for both lower limbs. The analysis of $\mathrm{SI}_{j}$ indices enables the assessment of the asymmetry of pelvic movements and movements in the joints of the lower limbs. In terms of the patient subjected to the tests, the asymmetry of movements was observed in relation to HPIE and AIE. Reference scientific publications did not contain works where gait symmetry was assessed on the basis of indices (e.g., GGI, GDI) or parameters making up such indices. On the other hand, it is possible to find many publications where the assessment of gait symmetry is based on gait-related parameters, including, among others, time-spatial, 
Table 6. Characteristics of gait indexes and their mathematical algorithm

\begin{tabular}{|c|c|c|c|c|c|c|c|}
\hline \multirow[b]{2}{*}{$\begin{array}{l}\text { Gait } \\
\text { Index }\end{array}$} & \multirow[b]{2}{*}{$\begin{array}{l}\text { Authors } \\
\text { (year) }\end{array}$} & \multirow[b]{2}{*}{ Parameters } & \multirow[b]{2}{*}{$\begin{array}{l}\text { Mathematical } \\
\text { algorithm }\end{array}$} & \multicolumn{4}{|c|}{ Method makes it possible to ... } \\
\hline & & & & $\begin{array}{c}\text { Identify } \\
\text { gait using } \\
\text { a single } \\
\text { numerical } \\
\text { value }\end{array}$ & $\begin{array}{l}\text { evaluate } \\
\text { movements } \\
\text { in } \\
\text { individual } \\
\text { joints }\end{array}$ & $\begin{array}{l}\text { evaluate } \\
\text { movements } \\
\text { in } \\
\text { subsequent } \\
\text { moments }\end{array}$ & $\begin{array}{l}\text { assess } \\
\text { the } \\
\text { symmetry } \\
\text { of gait }\end{array}$ \\
\hline GGI & $\begin{array}{l}\text { Schutte L.M. } \\
\text { et al. }(2000) \\
{[17]}\end{array}$ & $\begin{array}{l}\text { percentage of stance phase (time of } \\
\text { toe off), walking speed normalized } \\
\text { by the length of the lower limb, fre- } \\
\text { quency of making steps - cadence, } \\
\text { mean forward tilt of the pelvis in the } \\
\text { sagittal plane, range of the pelvic } \\
\text { motion in the sagittal plane, mean } \\
\text { pelvic rotation in the transverse } \\
\text { plane, minimum flexion of the hip } \\
\text { joint in the sagittal plane, range of } \\
\text { the hip joint motion in the sagittal } \\
\text { plane, peak abduction of the hip } \\
\text { joint in swing, mean rotation of the } \\
\text { hip joint in stance, knee joint flex- } \\
\text { ion at the initial contact with the } \\
\text { ground, time to the peak knee flex- } \\
\text { ion, range of flexion and extension } \\
\text { of the knee joint, peak dorsiflex- } \\
\text { ion in stance, peak dorsiflexion in } \\
\text { swing, mean foot progression } \\
\text { angle in stance }\end{array}$ & $\begin{array}{l}\text { is a measure of the distance between } \\
\text { sets of separate variables defining the } \\
\text { patient's gait pattern and the mean of } \\
\text { such variables in healthy persons; } \\
\text { the algorithm uses the Principal } \\
\text { Component Analysis (PCA) }\end{array}$ & yes & $\begin{array}{l}\text { yes } \\
\text { (on the } \\
\text { basis of } \\
\text { kinematic } \\
\text { variables } \\
\text { building } \\
\text { the index) }\end{array}$ & no & no \\
\hline GDI & $\begin{array}{l}\text { Schwartz M.H. } \\
\text { \& Rozumalski A. } \\
\text { (2008) [20] }\end{array}$ & $\begin{array}{l}\text { pelvic obliquity, pelvic tilt, pelvic ro- } \\
\text { tation, hip abd-adduction, hip flex- } \\
\text { ion-extension, hip rotation, knee flex- } \\
\text { ion-extension, ankle dors-plantar- } \\
\text { flexion, foot progression }\end{array}$ & $\begin{array}{l}\text { is defined as a general measure } \\
\text { of the distance between the set of } \\
\text { kinematic variables of pathological } \\
\text { gait and the mean obtained in rela- } \\
\text { tion to the standard (identified in } \\
\text { relation to every } 2 \% \text { of the gait cy- } \\
\text { cle); the algorithm is based on the } \\
\text { SVD of matrix }\end{array}$ & yes & $\begin{array}{l}\text { yes } \\
\text { (on the } \\
\text { basis of } \\
\text { kinematic } \\
\text { variables } \\
\text { building } \\
\text { the index) }\end{array}$ & $\begin{array}{l}\text { yes } \\
\text { (on the } \\
\text { basis of } \\
\text { kinematic } \\
\text { variables } \\
\text { building } \\
\text { the index) }\end{array}$ & no \\
\hline $\begin{array}{l}\text { GPS } \\
\& \text { MAP }\end{array}$ & $\begin{array}{l}\text { Baker at al. } \\
(2009) \text { [2] }\end{array}$ & $\begin{array}{l}\text { pelvic obliquity, pelvic tilt, pelvic } \\
\text { rotation, hip abd-adduction, hip } \\
\text { flexion-extension, hip rotation, knee } \\
\text { flexion-extension, ankle dors-plantar- } \\
\text { flexion, foot progression }\end{array}$ & $\begin{array}{l}\text { is a general measure of the distance } \\
\text { between the set of kinematic variables } \\
\text { of pathological gait and the mean ob- } \\
\text { tained in relation to the standard } \\
\text { (identified in the gait cycle). The } \\
\text { essence of the GPS algorithm consists } \\
\text { in calculating the root-mean-square } \\
\text { difference between the average } \\
\text { sector related to the standard and } \\
\text { the vector related to the patient. } \\
\text { Values obtained in relation to the } \\
\text { analysed kinematic parameters are } \\
\text { presented in the form of a bar chart } \\
\text { creating the so-called maps of gait } \\
\text { (MAP) }\end{array}$ & yes & yes & no & no \\
\hline $\begin{array}{l}\text { GDI- } \\
\text {-Kinetic }\end{array}$ & $\begin{array}{l}\text { Schwartz M.H. } \\
\text { \& Rozumalski } \\
\text { A. (2011) [21] }\end{array}$ & $\begin{array}{l}\text { sagittal hip moment, coronal hip mo- } \\
\text { ment, sagittal knee moment, coronal } \\
\text { knee moment, sagittal ankle moment, } \\
\text { coronal ankle moment, hip power, } \\
\text { knee power, ankle power }\end{array}$ & $\begin{array}{l}\text { is defined as a general measure of } \\
\text { the distance between the set of dy- } \\
\text { namic variables of pathological gait } \\
\text { and the mean obtained in relation to } \\
\text { the standard (identified in relation to } \\
\text { every } 2 \% \text { of the gait cycle); the algo- } \\
\text { rithm is based on the SVD of matrix }\end{array}$ & yes & no & no & no \\
\hline GVI & $\begin{array}{l}\text { Gouelle A. } \\
\text { et. al. (2013) } \\
\text { [5] }\end{array}$ & $\begin{array}{l}\text { step length, stride length, step time, } \\
\text { stride time, swing time, stance time, } \\
\text { single support time, double support } \\
\text { time, velocity, and standard devia- } \\
\text { tions (SD) of each parameter }\end{array}$ & $\begin{array}{l}\text { is defined as a general measure of } \\
\text { the distance between the set of time- } \\
\text { spatial variables of pathological gait } \\
\text { and the mean obtained in relation to the } \\
\text { standard; the algorithm uses the Princi- } \\
\text { pal Component Analysis (PCA), GVI } \\
\text { is scaled in the same manner as GDI }\end{array}$ & yes & no & no & no \\
\hline
\end{tabular}


Table 6 continued

\begin{tabular}{|c|c|c|c|c|c|c|c|}
\hline $\begin{array}{l}\text { GKI, } \\
\text { GSI } \\
\& \text { GDP }\end{array}$ & $\begin{array}{l}\text { Jochymczyk- } \\
\text {-Woźniak et al. }\end{array}$ & $\begin{array}{l}\text { ankle dors-plantarflexion (AFE), foot } \\
\text { progression (AIE), knee flexion-ex- } \\
\text { tension (KFE), knee valgus-varus } \\
\text { (KAA), knee rotation (KIE), hip flex- } \\
\text { ion-extension (HPFE), hip ab- } \\
\text { duction-adduction (HPAA), hip rota- } \\
\text { tion (HIPIE), pelvic tilt (PTILT), } \\
\text { pelvic obliquity (POBLI), pelvic } \\
\text { rotation (PROT) }\end{array}$ & $\begin{array}{l}\text { the comprehensive gait evaluation meth- } \\
\text { od is based on the gait kinematic } \\
\text { index (GKI), gait symmetry index (GSI) } \\
\text { and gait deviation profile (GDP) pre- } \\
\text { sented using a coloured scale enabling } \\
\text { the assessment of gait deviations in } \\
\text { successive moments. } \\
\text { The mathematical algorithm is rela- } \\
\text { tively simple and involves the determi- } \\
\text { nation of the difference between results } \\
\text { of movement kinematic obtained in } \\
\text { relation to the patient and the aver- } \\
\text { age value obtained in relation to the } \\
\text { standard in each percentage of the } \\
\text { gait cycle. }\end{array}$ & yes & yes & yes & yes \\
\hline
\end{tabular}

kinematic or dynamic parameters [3], [17], [21], [24]. One of the features of proper gait is its symmetry [3], and, because of this fact, methods for gait evaluation should take the aforesaid aspect of gait into consideration.

The new comprehensive method of gait pathology evaluation involving the Gait Kinematics Index (GKI), Global Symmetry Index (GSI) and the Gait Deviations Profile (GDP) can be recognised as a very useful tool in the diagnostics of locomotor functions in patients with locomotor system dysfunctions. In contrast to other gait indexes such as, e.g., GGI, GDI, GDIKinetic, GPS, or GVI [2], [5], [7], [17], [20], [21], the proposed comprehensive method makes it possible to globally characterise the patient's gait not only by means of one numerical value. It also applies indices assessing the movement of pelvis and movement in the joints of the lower limbs. In addition, the method enables the presentation of the characteristics of locomotor functions in a clear graphical form as the Gait Deviations Profile.

The characteristics of the proposed gait evaluation method compared with other indicative methods referred to in available scientific publications are presented in Table 6. The already known gait indices are characterised by complicated mathematical algorithms. Nearly all indices enable the evaluation of gait using one non-dimensional numerical value. However, clinicians find information represented by a single index value unclear. Doubts concerning the clinical application of gait indices can be found in scientific publications by other authors [13], [14]. According to Molloy et al. [14], the assessment of locomotor functions based on a single numerical value lacks information about movement in individual joints and successive moments. Tests performed by McMulkin et al. [13] led to conclusions that the GGI (Gillette Gait Index) does not offer any representative benefits related to gait assessment in comparison with the GDI (Gait Deviation Index). The GGI is less sensitive when describing treatment results, does not possess parametric features nor does it allow intuitive interpretation. In addition, the GGI is assumedly dedicated to patients with infantile cerebral palsy and the parameters proposed by clinicians, as indicated by the authors of this work, precisely characterise the gait of patients suffering from the ICP. Because of this, parameters making up the GGI will probably not properly characterise the gait of patients with other locomotor system-related problems [17].

Taking into considerations the doubts aroused by the evaluation of gait based on a single numerical value and the fact that it does not provide a complex diagnostic method, it seems that the new comprehensive method of gait pathology evaluation: Gait Kinematics Index (GKI), Global Symmetry Index (GSI) and Gait Deviations Profile (GDP) can find applications in clinical establishments and movement analysis laboratories. Unlike other indicative methods, the new comprehensive method makes it possible to evaluate movements in individual joints and successive moments as well as enables the assessment of gait symmetry (Table 6).

\section{Limitations}

The authors fully realise the limitations of this work. The article presents results concerning healthy persons and one patient suffering from locomotor system dysfunctions. It is necessary to test and validate the proposed method of gait evaluation in relation to a larger number of patients with locomotor system dysfunctions. It also appears justified to correlate values of GKI with other gait-related indices or scales of observation-based assessment as well as to discuss the functionality of the proposed tool with clinicians. 


\section{Conclusions}

The article discusses the concept of a new comprehensive method of gait pathology evaluation based on Gait Kinematics Index (GKI), Global Symmetry Index (GSI) and Gait Deviations Profile (GDP). It also presents in detail an algorithm used to determine the GKI and variables building it as well as the possible evaluation of gait deviations by means of coloured GDP maps. The diagnostic functionality of the proposed method is illustrated with a case of a patient with locomotor system dysfunctions. The method enabling the evaluation of locomotor functions has been compared with other indicative methods discussed in related scientific publications (Table 6).

In authors' opinion, the method is less complex than, for instance, the mathematical algorithm of the GGI index using the Principal Component Analysis (PCA). The algorithm of the proposed method is based on 6 uncomplicated equations, which can be implemented in any calculation sheet, such as Microsoft Excel. The new gait evaluation method makes it possible to identify gait using a single numerical value, evaluate movements in individual joints and in subsequent moments as well as to assess the symmetry of gait.

\section{References}

[1] Ammann-Reiffer C., Bastiaenen C.H.G., Klöti C., Van Hedel H.J.A., Concurrent Validity of Two Gait Performance Measures in Children with Neuromotor Disorders, Phys. Occup. Ther. Pediatr., 2019, 39 (2), 181-192.

[2] BaKer R., McGinley J.L., Schwartz M.H., Beynon S., Rozumalski A., Graham H.K., Tirosh O., The gait profile score and movement analysis profile, Gait and Posture, 2009, 30 (3), 265-269.

[3] Barton G.J., Hawken M.B., Scott M.A., Schwartz M.H., Movement Deviation Profile: A measure of distance from normality using a self-organizing neural network, Hum. Mov. Sci., 2012, 31, 284-294.

[4] BŁazkiewicz M., Wiszomirska I., Wit A., Comparison of four methods of calculating the symmetry of spatialtemporalparameters of gait, Acta of Bioengineering and Biomechanics, 2014, 16 (1), 29-35.

[5] Michael H., Schwartz Gouelle A., Mégrot F., Presedo A., Husson I., Yelnik A., Penneçot G.F., The gait variability index: a new way to quantify fluctuation magnitude of spatiotemporal parameters during gait, Gait Posture, 2013, 38, 461-465.

[6] Gunel M.K., Mutlu A., Tarsuslu T., Livanelioglu A., Relationship among the Manual Ability Classification System (MACS), the Gross Motor Function Classification System (GMFCS), and the functional status (WeeFIM) in children with spastic cerebral palsy, Springer, 2009, 168, 477-485.
[7] Guzik A., Drużbicki M., Przysada G., Szczepanik M., BAZARNIK-Mucha K., KwOleK A., The use of the Gait Variability Index for the evaluation of individuals after a stroke, Acta of Bioengineering and Biomechanics, 2018, 20 (2), 171-177.

[8] Haley S.M., Coster W.J., KaO Y-C., Dumas H.M., Fragala-Pinkham M.A., Kramer J.M., Ludlow L.H., MOED R., Lessons fron Use of Pediatric Evaluation of Disability Inventory (PEDI): Where Do We Go From Here?, Pediatr. Phys. Ther., 2010, 22, 69-75.

[9] JochymCZYK-WoźNiaK K., NowaKowsKa K., Michnik R., GzIK M., KowALCZYKOwSKI D., Three-dimensional adults gait pattern - reference data for healthy adults aged between 20 and 24, [in:] Innovation in biomedical engineering (eds.) M. Gzik, E. Tkacz, Z. Paszenda, E. Piętka, Cham: Springer International Publishing, Advances in Intelligent System and Computing, 2019, Vol. 925, 2194-5357, 169-176.

[10] JOCHYMCZYK-WoŹNIAK K., NOWAKOWSKA K., POLECHOŃSKI J., SŁADCZYK S., MichNik R., Physiological Gait versus Gait in VR on Multidirectional Treadmill - Comparative Analysis, Medicina, 2019, 55 (9), 517.

[11] JurkojĆ J., Wodarski P., Michnik R., Bieniek A., Gzik M., GraneK A., The Standard Deviation of Differential Index as an innovation diagnostic tool based on kinematic parameters for objective assessment of a upper limb motion pathology, Acta of Bioengineering and Biomechanics, 2017, 19 (4), 77-87.

[12] JuRkojĆ J., Wodarski P., Michnik R., NowakowsKa K., BIENIEK A., GZIK M., The Upper Limb Motion Deviation Index: A new comprehensive index of upper limb motion pathology, Acta of Bioengineering and Biomechanics, 2017, 19 (2), $175-185$.

[13] McMulkin M.L., MacWilliams B.A., Application of the Gillette Gait Index, Gait Deviation Index and Gait Profile Score to multiple clinical pediatric populations, Gait and Posture, 2015, 41, 608-612.

[14] Molloy M., McDowell B.C., Kerr C., Cosgrove A.P., Further evidence of validity of the Gait Deviation Index, Gait and Posture, 2010, 31, 479-482.

[15] NOWAKOWSKa K., MichNIK R., JOCHYMCZYK-WoźNIAK K., Jurkojć J., Mandera M., Kopyta I., Application of gait index assessment to monitor the treatment progress in patients with cerebral palsy, [in:] Information Technologies in Medicine 5th International Conference, ITIB, Kamień Śląski, Poland, June 20-22, 2016 Proceedings, E. Piętka, P. Badura, J. Kawa, W. Wieclawek (Eds.), Cham: Springer, Advances in Intelligent System and Computing, 2016, 472, Vol. 2, 75-85.

[16] RutKowska-Kucharska A., Kowal M., Winiarski S., Relationship between asymmetry of gait and muscle torque in patients after unilateral transfemoral amputation, Applied Bionics and Biomechanics, 2018, Article ID 5190816, https:// doi.org/10.1155/2018/5190816

[17] Sadeghi H., Allard P., Prince F., Labelle H., Symmetry and limb dominance in able-bodied gait: a review, Gait and Posture, 2000, 12 (1), 34-45.

[18] Salbach N.M., Gullcher S.J.T., Jaglal S.B., Physical therapists' perceptions and use of standardized assessments of walking ability post-stroke, J. Rehabil. Med., 43 (6), 543-549.

[19] SchUTTE L.M. et al., An index for quantifying deviations from normal gait, Gait \& Posture, 2000, 11, 25-31.

[20] SChwarTz M.H., RozumalsKi A., The gait deviation index: A new comprehensive index of gait pathology, Gait and Posture, 2008, 28, 351-357. 
[21] Schwartz M., Rozumalski A., The GDI-Kinetic: A new index for quantifying kinetic deviations from normal gait, Gait and Posture, 2011, 33, 730-732.

[22] Syczewska M., Graff K., Kalinowska M., SzczerbiK E., DOMANIECKI J., Influence of the structural deformity of the spine on the gait pathology in scoliotic patients, Gait and Posture, 2012, 35, 209-213.

[23] Winiarski S., Dubiel-Wuchowicz K., RUTKOWSKAKUCHARSKA A., Symmetry of support scull and vertical position stability in synchronized swimming, Acta of Bioengineering and Biomechanics, 2013, 15 (1), 113-122.
[24] Winiarski S., Rutkowska-Kucharska A., Pozowski A., AleKSANDROWICZ K., A New Method of Evaluating the Symmetry of Movement Used to Assess the Gait of Patients after Unilateral Total Hip Replacement, Applied Bionics and Biomechanics, 2019, 7863674, DOI: 10.1155/2019/7863674.

[25] Vaughan, C.L., Davis, B.L., O'Connor, J.C., Dynamics of Human Gait, Kiboho Publishers: Cape Town, South Africa, 1999.

[26] ŻUK M., TRZECIAK M., Anatomical protocol for gait analysis: joint kinematics measurement and its repeatability, Journal of Theoretical and Applied Mechanics, 2017, 55 (1), 369-376. 